\title{
AS JANELAS QUEBRADAS DA VIOLÊNCIA DOMÉSTICA
}

\author{
Márcia Haydée Porto de Carvalho* \\ Maicy Milhomem Moscoso Maia*
}

\section{RESUMO}

O presente artigo analisa a teoria das janelas quebradas de James Q. Wilson e George L. Kelling e verifica a sua pertinência aos casos de violência doméstica, partindo do entendimento de que estes delitos configuram-se como um ciclo tendente ao agravamento. Serão examinados os dados estatísticos sobre a violência contra a mulher no Brasil (Atlas da Violência dos anos de 2017 e 2018), os Relatórios Estatísticos Anuais do Conselho Nacional de Justiça (2016, 2017 e 2018) e pesquisa bibliográfica que subsidie o estabelecimento de uma relação proveitosa entre a teoria das janelas quebradas e a violência doméstica contra a mulher.

Palavras-chave: Teoria das janelas quebradas. Violência doméstica. Criminalidade. Gestão judiciária. Dados estatísticos. Ineficiência.

\section{THE BROKEN WINDOWS OF DOMESTIC VIOLENCE}

\begin{abstract}
This article analyzes the theory of broken windows by James Q. Wilson and George L. Kelling and verifies its relevance to cases of domestic violence, starting from the understanding that these crimes are configured as an aggravating cycle. Statistical data on violence against women in Brazil (2017 and 2018 Atlas of Violence), the Annual Statistical Reports of the National Council of Justice (2016, 2017 and 2018) and bibliographic research to support the establishment of a fruitful relationship between broken window theory and domestic violence against women.
\end{abstract}

Keywords: Broken windows theory. Domestic violence. Crime. Judicial management. Statistic data. Inefficiency.

\section{INTRODUÇÃO}

A violência doméstica contra a mulher é tema recorrente desde a edição da Lei Maria da Penha, em 2006, principalmente porque referida norma inovou ao atribuir a proteção das mulheres vítimas desse tipo de violência à uma rede multidisciplinar e integrada de órgãos,

\footnotetext{
* Doutora em Direito do Estado pela PUC/SP. Professora da Graduação em Direito e do Mestrado em Direito e Instituições do Sistema de Justiçada Universidade Federal do Maranhão. Professora pesquisadora do curso de Direito no UNICEUMA. Promotora de Justiça do Estado do Maranhão.

* Mestranda do programa de pós-graduação em Direito e Instituições do Sistema de Justiça, da Universidade Federal do Maranhão.
} 
além de voltar-se à promoção da isonomia entre homens e mulheres, através da discriminação positiva.

Ao longo dos anos, o aparato legal de proteção às mulheres vem sendo incrementado. Recentemente, o feminicídio foi inserido como qualificadora do crime de homicídio, através da alteração legislativa feita pela 13.105/2015, o crime de descumprimento de medidas protetivas de urgência foi tipificado, conforme alteração na Lei $\mathrm{n}^{\circ}$. 11.340/2006, realizada pela Lei $\mathrm{n}^{\circ}$. 13.641/2018, assim como foi ampliado o rol de legitimados para a concessão de medidas protetivas de urgência, com a inclusão do delegado de policial e até pelo próprio policial, nos termos da alteração promovida pela Lei nº $13.827 / 2019$.

Inobstante todos estes avanços legislativos, os dados de violência contra a mulher, apontados nos Atlas da Violência dos anos de 2017 e 2018 - mapeamento realizado pelo Instituto de Pesquisa Econômica Aplicada (IPEA) sobre as taxas de violência nacional apontam o crescimento no número de mortes de mulheres.

Os dados do Conselho Nacional de Justiça (CNJ) também indicam aumento na demanda destes crimes junto ao poder judiciário, o que demonstra que as mulheres têm cada vez mais procurado a salvaguarda da justiça em face de seus agressores. Entretanto, essa relação entre o aumento das taxas de violência contra a mulher e o crescimento da demanda destas vítimas junto ao poder judiciário pode indicar que, em algum aspecto, a política criminal ou a atuação das instituições do sistema de justiça tem falhado em prevenir crimes desta natureza.

Ora, antes de tudo, é necessário observar as peculiaridades do fenômeno social que é a violência doméstica: um ciclo de agressões repetitivas e tendentes ao agravamento. O IPEA constatou que a grande maioria dos homicídios praticados contra homens se dá nas ruas, enquanto as mulheres, em sua maioria, são assassinadas dentro do contexto doméstico. Apesar disso, em 2016, o CNJ registrou que, dentre os 20 (vinte) assuntos de maior incidência nas Varas e Juizados Especializados, ou seja, no primeiro grau de jurisdição, figuravam os crimes contra a liberdade pessoal/ameaça, violência doméstica contra a mulher e lesão corporal decorrente de violência doméstica.

A hipótese que se levanta neste trabalho é a possibilidade do crescimento dos números relacionados à violência doméstica contra as mulheres estar relacionado à percepção que estes dados passam: apenas os crimes mais violentos - como o feminicídio ou as lesões corporais graves, aqueles que tomam as capas dos noticiários e ensejam campanhas em redes 
sociais - são punidos. Os crimes cotidianos, os insultos, os constrangimentos, as ameaças e as vias de fato reiteradamente praticadas, isto é, os "crimes menores", não ensejam comoção e, por isso, são negligenciados pela sociedade, pelos especialistas e pelo próprio poder judiciário.

Neste contexto, a broken windows theory, dos americanos Wilson e Kelling (1982), surge como uma opção de arcabouço lógico e teórico, capaz de subsidiar ações das instituições do sistema de justiça e políticas públicas do poder executivo, voltadas não apenas para a prevenção, mas também à repressão do start do ciclo da violência doméstica, que se não combatido em sua origem, evolui para agravamentos que podem ser irreversíveis.

Assim, o presente estudo se divide em três eixos. Primeiramente, serão tecidos os conceitos e premissas básicas da broken windows theory, de Wilson e Kelling (1982), assim como o contexto em que esta teoria foi elaborada, as críticas direcionadas a ela e a proposta de aplicação desta teoria aos crimes praticados sob os auspícios da violência doméstica.

No tópico seguinte, a violência doméstica será abordada em suas especificidades, com ênfase na sua configuração em espiral ascendente, explicando-se este conceito e como é possível percebê-lo no dia-a-dia. Em seguida, serão analisados os dados divulgados pelo IPEA, referente aos Atlas da Violência dos anos de 2017 e 2018 e estatísticas do CNJ, referentes à atuação do poder judiciário em relação à clientela formada por vítimas de violência doméstica.

Finalmente, no tópico 4, a broken windows theory será correlacionada à violência doméstica e às suas especificidades, oportunidade em que se demonstrará como essa teoria serve bem à política criminal de proteção às mulheres, podendo promover significantes resultados nesta seara.

Para o desenvolvimento deste artigo, foram utilizadas como estratégias metodológicas a análise de conteúdos dos dados divulgados pelo IPEA e CNJ, assim como à legislação afeta ao tema, além de pesquisa bibliográfica.

\section{A BROKEN WINDOWS THEORY}

Em março de 1982, dois cientistas sociais da Universidade de Harvard, James Wilson e George Kelling, publicaram na revista The Atlantic Monthly, a broken windows 
theory, segundo a qual pequenos delitos e desordens fomentam a percepção de desinteresse e despreocupação da sociedade sobre determinados valores.

Inicialmente, é essencial entender o contexto em que os estudos de Wilson e Kelling (1982) foram produzidos. A pesquisa dos autores destinava-se a avaliar o impacto da medida de substituição das patrulhas motorizadas (viaturas de polícia) em bairros de Nova Jersey por patrulhas-ambulantes (foot-patrol), adotada em meados dos anos 1970, durante a implantação do Safe and Clean Neighborhoods Program, criado para promover a qualidade de vida comunitária em 28 (vinte e oito) cidades. Referida medida recebeu uma série de críticas, inobstante o governo estivesse bastante entusiasmado com a ideia.

Os críticos da foot-patrol entendiam que ela reduzia a mobilidade da polícia, pois dificultava a resposta aos chamados dos cidadãos, assim como enfraquecia o controle dos policiais pelos seus superiores. Além disso, alguns policiais também viam na foot-patrol um trabalho muito árduo ${ }^{1}$, pois os matinha na rua em tempo de frio, em noites chuvosas, o que poderia comprometer a qualidade das suas abordagens.

Passados 05 anos após a implementação da foot-patrol em Nova Jersey, a Police Foundation $^{2}$, em Washington, D. C., publicou uma análise deste projeto, com base na observação da foot-patrol realizada em Newark. O estudo realizado a partir das análises de Newark concluiu que a foot-patrol não reduziu as taxas de criminalidade naquela localidade. No entanto, os pesquisadores da Police Foundation observaram que os moradores dos bairros patrulhados a pé pareciam se sentir mais seguros do que os moradores de outras áreas, ao ponto de acreditarem que a criminalidade havia de fato diminuído, chegando até a tomarem menos cautelas contra a insegurança (como ficar com as portas de casa destrancadas). Ao mesmo tempo, os pesquisadores da Police Foundation constataram que os policiais da footpatrol se sentiam mais valorizados pela população local e estavam mais satisfeitos com o seu trabalho.

O desafio que se apresentou a Wilson e Kelling (1982) era explicar os bons resultados obtidos pela foot-patrol, sob a ótica da satisfação tanto dos moradores do bairro patrulhado, quanto dos patrulheiros, em contraponto aos números da criminalidade que permaneceram os mesmos, sendo até possível que tivessem aumentado. Para tanto, os autores

\footnotetext{
${ }^{1}$ Wilson e Kelling (1982) destacaram que, em alguns departamentos, a designação para a foot-patrol foi elevada ao patamar de punição disciplinar.

${ }^{2}$ George L. Kelling era integrante da Police Foundation, na época e participou da pesquisa que avaliou os resultados da foot-patrol em Newark, Nova Jersey.
} 
recorreram aos experimentos de Philip Zimbardo, psicólogo da Universidade de Stanford, que em 1969, relatou uma série de experimentos sobre o comportamento humano diante de indícios de desordem. Wilson e Kelling (1982) tomaram o experimento de Zimbardo que consistia em abandonar dois carros idênticos em duas vias públicas: uma no bairro Bronx, Nova York e outro no bairro Palo Alto, California.

O primeiro bairro era conhecido por ser pobre e conflituoso, enquanto o segundo era abastado e tranquilo. No Bronx, tão logo o carro foi abandonado pelo pesquisador, os membros de uma família - pai, mãe e filho - removeram-lhe o radiador e a bateria. Em menos de 24 (vinte e quatro) horas tudo o que poderia ter valor no carro abandonado no Bronx foi levado. Não havendo mais o que pudesse ser retirado do veículo, Philip Zimbardo observou que se iniciaram as depredações: os vidros foram quebrados, as portas amassadas, os estofados rasgados e, finalmente, crianças fizeram do carro playground. Neste caso, Zimbardo observou que as pessoas que depredaram o veículo fugiam do estereótipo de delinquência ${ }^{3}$.

O segundo veículo, abandonado em Palo Alto, California, permaneceu intocado por mais de 01 (uma) semana. Passado esse tempo, Philip Zimbardo decidiu quebrar parte do carro com uma marreta e, depois disso, pessoas se aglomeraram ao redor do veículo, de modo que, em poucas horas, o carro estava revirado de ponta a cabeça, completamente destruído. Também neste caso, Zimbardo observou que os indivíduos que vandalizaram o veículo eram pessoas que passariam por comuns e respeitáveis ${ }^{4}$.

Em face dos achados de Philip Zimbardo, Wilson e Kelling (1982) concluíram que, apesar das claras diferenças entre os dois bairros que figuraram no experimento, ambos estão igualmente passíveis de violência e vandalismo,

[...] Untended property becomes fair game for people out for fun or plunder, and even for people who ordinarily would not dream of doing such things and who probably consider themselves law-abiding. Because of the nature of community life in the Bronx - its anonymity, the frequency with which cars are abandoned and things are stolen or broken, the past experience of "no one caring" - vandalismo begins much more quickly than it does in staid Palo Alto, where people have come to believe that private possessions are cared for, and that mischievous behavior is costly. But vandalism can occur anywhere once communal barriers: the sense of mutual regard and the obligations of civility are lowered by actions that seem to signal that "no one cares" [...]. (WILSON; KELLING, 1982, n. p.) ${ }^{5}$.

\footnotetext{
${ }^{3}$ Segundo os autores, “[...] Most of the adult 'vandals' were well dressed, apparently clean-cut whites [...]" (WILSON; KELLING, 1982, n. p.)

4 “[...] Again, the 'vandals' appeared to be primarily respectable whites [...]” (WILSON; KELLING, 1982, n. p.)

${ }^{5}$ Em tradução livre: “[...] Devido à natureza da vida comunitária no Bronx - seu anonimato, a freqüência com que os carros são abandonados e as coisas são roubadas ou quebradas, a experiência passada de 'ninguém se importar' - o vandalismo começa muito mais rapidamente do que em Palo Alto, onde as pessoas passaram a
} 
Desta maneira, os autores estabeleceram a relação entre desordem e criminalidade e, em maior perspectiva, entre a não repressão de pequenos delitos e a sua evolução para a criminalidade violenta, formulando a alegoria da janela da fábrica que é quebrada e que, permanecendo assim, passa a mensagem de que pode-se ir além dessa inocente ousadia, sem que maiores consequências aconteçam, porque ninguém se importa:

[...] Algumas conclusões da teoria são: há relação de causalidade entre desordem e criminalidade, entre a não repressão a pequenos delitos e a criminalidade violenta. Se uma janela de uma fábrica ou prédio é quebrada e não é imediatamente consertada as pessoas que por ali passam tendem a concluir que ninguém se importa, que não há autoridade zelando pela manutenção da ordem. Assim, as pessoas começariam a atirar pedras para quebrar as demais janelas. Inicia-se assim a decadência do local, com pequenas desordens levando a grandes desordens. Nessa lógica, diante do abandono de comunidades pela autoridade responsável, desocupados, desordeiros e pessoas com tendências criminosas se sentiriam à vontade para ali fazer negócios ou mesmo morar, levando outros moradores a desejarem se mudar para outros locais. A pequena desordem gera a ideia de deterioração, de desinteresse e de despreocupação nas pessoas. A percepção da ausência de lei, normas e regras tende a levar à quebra dos códigos de Convivência [...]. (ODON, 2016, p. 2).

A teoria de Wilson e Kelling (1982) repercutiu em 1993, quando William Bratton, então comissário de polícia do prefeito de Nova York, Rudy Giuliani, baseou a política zero tolerance, na teoria das janelas quebradas. A zero tolerance agiu incisivamente contra as incivilidades públicas, a exemplo da vadiagem nas ruas, pessoas sem-teto, mendigos, usuários de entorpecentes, adolescentes barulhentos, pichadores, pessoas que jogavam lixo ou urinavam em vias públicas, bêbados e demais categorias de desordeiros. Como destaca Odon (2016), entre os anos de 1993 e 1998, houve o aumento de 40\% no número de detenções por delitos menores realizadas em Nova York, além de considerável queda nas taxas de crime no decorrer dos anos.

Mesmo baseando-se na teoria das janelas quebradas, a política zero tolerance não se confundia com aquela, pois, tinha como componente principal o aumento da capacidade do aparato de vigilância e a resposta mais contundente da autoridade policial. Odon (2016, p. 34) resume os pontos principais da zero tolerance:

[...] (a) uma ampla reestruturação burocrática no Departamento de Polícia de Nova Iorque (descentralização de serviços, achatamento de níveis hierárquicos, demissão em massa de policiais graduados e a responsabilização direta de comissionários de

acreditar que posses são cuidadas e esse comportamento travesso é custoso. Mas o vandalismo pode ocorrer em qualquer lugar uma vez que as barreiras comunitárias - o senso de respeito mútuo e as obrigações de civilidade são reduzidas a ações que parecem sinalizar que 'ninguém se importa' [...] (WILSON; KELLING, 1982, n. p.) 
bairro, cuja remuneração e promoção passaram a depender, em parte, dos resultados obtidos no combate à criminalidade), (b) uma grande expansão dos recursos humanos e financeiros (o número de policiais pulou de $27.000 \mathrm{em} 1993$ para 41.000 em 2001) e (c) o desenvolvimento de um sistema informático de coleta e compartilhamento de dados que permitia acompanhar em tempo real a evolução e distribuição dos incidentes criminosos [...].

Apesar do sucesso propagado pelos órgãos oficiais sobre a política zero tolerance, a teoria sob a qual essa política se fundava, recebeu várias e duras críticas. Odon (2016) menciona as críticas de Robert J. Sampson (2012), de que a teoria das janelas quebradas apoia-se muito mais no interesse dos moradores de um bairro em intervir nesse espaço em nome do bem comum, do que uma relação necessária de causalidade entre desordem e criminalidade. Mattos (2018) reforça o posicionamento de Sampson (2012), de que não existe coerência na relação entre desordem e criminalidade:

[...] A tese central da Teoria das Janelas Quebradas é que incivilidades públicas (ou desordens) propiciam a ocorrência de crimes por indicarem que a comunidade não se importa com a vizinhança. Sampson critica essa proposição de duas maneiras principais: a. a distinção entre desordem e crime é essencialmente precária e deve, primeiramente, considerar que $b$. percepções de desordem são antes de tudo coletivas, compartilhadas coletivamente e reproduzidas socialmente (p. 123-134). Com isso, o autor defende que tanto o crime como as desordens são variáveis dependentes numa equação que reúne como preditores estabilidade residencial, desvantagens concentradas, eficácia coletiva, dentre outros. Em suma, para o autor, não há relação causal entre desordem e crime [...]. (MATTOS, 2018, p. 298).

São mencionadas também por ODON (2016), as críticas do jurista indiano C. R. Sridhar, de que a causa para a redução dos índices de criminalidade em Nova York não era unicamente a política zero tolerance, mas a conjugação de vários fatores, dentre eles, a bonança econômica, a redução da taxa de desemprego, que possibilitou a absorção pelo mercado da mão de obra desqualificada ociosa; a estabilização do mercado de drogas (crack), que passou a ser varejista e oligopólico e reduziu as disputas entre gangues locais; a redução do número de jovens, em virtude das morte por overdose, epidemias de AIDS e violência entre gangues; o papel de instituições sociais como a igreja, associações e escolas ao desenvolver campanhas de conscientização e prevenção, dentre outros fatores.

Tem-se ainda as críticas do francês Loïc Wacquant que, no artigo The "Scholarly Myths" of the New Law and Order Doxa (2006), sustentou que não foi a restauração da moral da norma que reduziu os índices de criminalidade em Nova York, mas sim o aumento e concentração da polícia e da repressão penal 
[...] When all is said and done, at the end of a painstaking examination of the question, the legal scholar Bernard Harcourt argues that, if the New York police department contributed to the decline in crime, it was not by reestablishing civility and communicating a message of stern refusal of impunity, but by the simple fact of having massively increased the intensity of the surveillance it wields: in 1990 Giuliani's city had thirty-eight police for every 100,000 inhabitants, as against twice that number ten years later, and their action was strongly targeted on dispossessed populations and districts. In short, it is the accentuation and concentration of police and penal repression, and not the moral mechanism of the restoration of the norm postulated by the so-called theory of Wilson and Kelling, that would account for police effectiveness in the case - itself still hypothetical - where policing would have played a significant role [...]. (WACQUANT, 2006, p. 106).

As críticas à teoria das janelas quebradas são severas, especialmente quando formuladas à luz da política nova-yorkina zero tolerance e das medidas concretas adotadas naquela época. No entanto, parece ser acertada a premissa de que a negligência do Estado perante pequenos delitos enseja o sentimento de "no one cares", fator que intensifica a sensação de impunidade e torna o ambiente favorável para as práticas criminosas. Deve-se considerar o contexto social em que os EUA se encontrava na época, assim como as prioridades que aquela sociedade, elencou como prioritárias em sua política criminal. Não custa lembrar que, falar de política criminal, envolve falar de escolhas valorativas de uma sociedade protegidas pelo Direito Penal, pois como bem observa Roxin (2002, p. 32), “[...] En la Política criminal incluye los métodos adecuados, em sentido social, para la lucha contra el delito, es decir, la llamada misión social del Derecho Penal [...]".

Nas democracias modernas, a política criminal goza da presunção de que se legitimou pela vontade do povo. Tomando-se como exemplo a realidade brasileira, a Constituição Federal determina que “[...] Todo o poder emana do povo, que o exerce por meio de representantes eleitos ou diretamente, nos termos desta Constituição [...]” (BRASIL, 1988, n. p.). Disso, se conclui que as escolhas feitas pela política criminal, ou seja, os valores e os bens jurídicos que serão tutelados pelo Estado através do Direito Penal, nada mais são do que escolhas feitas por aqueles que foram eleitos pelo povo para tal trabalho. O Direito Penal deve ser encarado como o instrumento pelo qual os fins da política criminal se transformam em módulos de validade legal e ambos devem estar conectados, pois só assim é possível alcançar o que é socialmente justo

[...] Pues el transformar los conocimientos criminológicos em exigencias políticocriminales y éstas, a su vez, en reglas jurídicas de lege lata oferenda, es un proceso, cuyos estadios concretos son de igual manera importantes y necesarios para el establecimiento de lo socialmente justo [...]. (ROXIN, 2002, p. 101-102). 
Mesmo com todas as críticas que pendem sob a teoria das janelas quebradas de Wilson e Kelling (1982), é inegável que ela foi utilizada como base teórica para a elaboração da conhecida política criminal nova-yorkina zero-tolerance, cujos resultados, ainda hoje são questionados. Indiscutível também que foi uma escolha daquela sociedade, naquela época, pelo o que julgavam ser socialmente justo. $O$ que se pretende neste trabalho é trazer a premissa básica da broken windows theory - a de que a negligência com pequenos delitos acarreta o cometimento de delitos maiores - para o universo brasileiro, no que tange aos crimes que envolvem violência doméstica contra a mulher, já que a proteção das mulheres, desde 2006, é uma escolha da nossa política criminal, embora a efetividade das punições seja questionável, conforme veremos a seguir.

\section{A EFETIVIDADE DA ATUAÇÃO DO PODER JUDICIÁRIO NOS CRIMES PRATICADOS SOB OS AUSPÍCIOS DA VIOLÊNCIA DOMÉSTICA}

A Constituição Federal de 1988 determina a igualdade entre homens e mulheres como direito fundamental (art. $5^{\circ}$, caput). Trata-se de igualdade formal, insculpida no texto constitucional para inibir do ordenamento jurídico desigualdades discriminatórias. No entanto para a concretização da igualdade substancial entre homens e mulheres, é igualmente necessário o nivelamento das desigualdades naturais e sociais que atingem esses indivíduos. Fernandes (2013, p. 84-85) esclarece:

[...] A igualdade entre homens e mulheres somente tem efetividade, assim, se reconhecida a posição jurídica de cada um e se houver instrumentos de tutela que permitam a realização prática desta igualdade. [...] A igualdade formal é ao mesmo tempo justa e discriminatória, na medida em que não reconhece as desigualdades. Homens e mulheres são iguais enquanto sujeitos de direitos, mas são também diferentes. Fisicamente, biologicamente, historicamente, economicamente e socialmente homens e mulheres são diferentes e agem de modo distinto [...].

Ora, a igualdade formal só é válida se ela possibilitar discriminações positivas, ou seja, ações afirmativas que permitam o nivelamento das desigualdades substanciais e inexoráveis entre homens e mulheres (físicas e biológicas), além das desigualdades impostas pela própria sociedade através das concepções de gênero.

Inobstante constar do texto constitucional, a isonomia entre homens e mulheres não se efetivava na prática, especialmente na seara dos crimes praticados contra mulheres no contexto familiar: injúrias, ameaças, constrangimentos ilegais, cárceres privados, lesões 
corporais em todas as suas modalidades e homicídios. Os casos de violência doméstica no Brasil sempre foram tratados como questões privadas e naturais da convivência conjugal ou familiar. Dias (2015) esclarece que a naturalização desta espécie de violência decorre do processo de dissimulação, destinado à invisibilização e negação da violência conjugal e familiar.

O senso comum social brasileiro assimilou ao longo da história que a divisão de espaços e funções dos indivíduos na sociedade ${ }^{6}$ é definida em grande parcela pelo gênero. Assim, ao homem cabe o espaço público e a responsabilidade por prover a família, enquanto à mulher restou o encastelamento no ambiente privado do lar, aonde deve ser submissa, amorosa e responsável pela educação da prole e administração da casa. Para Dias (2015), a rigidez destes papéis propicia a violência, justificada como compensação das falhas no desempenho das funções do gênero, socialmente idealizadas.

É neste contexto que o ciclo da violência doméstica se desenrola: uma série de etapas repetitivas, tendentes ao agravamento. São agressões de toda espécie, minúsculas na origem, mas que evoluem para crimes graves, envolvendo ofensas à integridade física e à vida. Se este ciclo não é interrompido, ele se configura em uma espiral ascendente de violência, podendo alcançar consequências irreversíveis.

[...] Primeiro vem o silêncio seguido da indiferença. Depois surgem reclamações, reprimendas, reprovações. Em seguida começam os castigos e as punições. A violência psicológica transforma-se em violência física. Os gritos transformam-se em empurrões tapas, socos, pontapés, num crescer sem fim. As agressões não se cingem à pessoa da vítima. $\mathrm{O}$ varão destrói seus objetos de estimação, a humilha diante dos filhos. Sabe que estes são os seus pontos fracos e os usa como "massa de manobra", ameaçando maltratá-los. [...] Depois de um episódio de violência, vem o arrependimento, pedidos de perdão, choro, flores, promessas etc. Cenas de ciúmes são justificadas como prova de amor, e a vítima fica lisonjeada. O clima familiar melhora e o casal vive uma nova lua de mel. Ela sente-se protegida, amada, querida, e acredita que ele vai mudar. Tudo fica bom até a próxima cobrança, ameaça, grito, tapa [...]. Forma-se um ciclo em espiral ascendente que não tem mais limite. (DIAS, 2015, p. 27-28).

\footnotetext{
${ }^{6}$ Em "Casa \& Rua", Damatta (1997) convida o leitor a refletir sobre a sociedade brasileira através da analogia entre as práticas sociais brasileiras e a forma como nós, brasileiros, nos comportamos em dois ambientes bem distintos: a nossa casa e a rua. Com essa alegoria, Roberto Damatta (1997) interpreta que a sociedade brasileira é "[...] fortemente motivada e tematizada pelas relações e pelas possibilidades de inventar pontes entre esses espaços [a casa, a rua e o outro mundo] [...]" (DAMATTA, 1997, p. 22). Para o autor, cada um desses espaços possui a sua ética própria e todo brasileiro adulto consegue agir adequadamente em cada um deles, sem necessidade de que isso seja formalmente ensinado. Na casa, se privilegia a pessoa e as interpretações oriundas desta esfera se dão de forma mais emocional e englobadora, dando conta de que todos são irmãos, por mais diferentes que sejam, já que pertencem a uma mesma pátria ou instituição social. É o local dos "supercidadãos", onde se pode fazer tudo o que não é permitido fazer na rua. Na rua, os contatos são mais rígidos e impessoais, de discurso disciplinado e defensor da letra fria da lei. Ao contrário do caráter agregador e fraterno do ambiente da casa, na rua se permite a exclusão, o banimento, a segregação e a condenação.
} 
A Lei Maria da Penha é um marco legislativo na proteção das mulheres vítimas de violência doméstica. Ela foi editada em 2006, por força das recomendações da Comissão Interamericana de Direitos Humanos (CIDH) da Organização dos Estados Americanos (OEA) para o Brasil, constantes do Relatório $n^{\circ}$. 54, publicado em 2001. As recomendações foram oriundas da demanda de Maria da Penha Maia Fernandes junto à $\mathrm{CIDH}$, que relatava episódios de violência institucional pelo poder judiciário brasileiro, em clara afronta ao que está previsto no art. $2^{\circ}$, alínea $c$, da Convenção de Belém do Pará ${ }^{7}$.

A vítima demonstrou a extrema tolerância do Brasil com a violência cometida contra ela pelo seu ex-marido ${ }^{8}$ : passaram-se mais de 15 anos, desde as agressões sofridas pela denunciante e, em vias de operar-se a prescrição sob os crimes praticados pelo agressor de Maria da Penha, a justiça brasileira ainda não tinha dado uma resposta definitiva para aquela vítima.

A CIDH entendeu que o Brasil, ao prolongar injustificadamente a demanda criminal de Maria da Penha, não foi capaz de organizar a sua estrutura para garantir os direitos das mulheres e que as autoridades judiciais brasileiras apresentavam ineficácia, negligência ou omissão, ao ponto de arriscar a impunidade do agressor de Maria da Penha. A morosa indulgência com que a justiça brasileira tratou o caso de Maria da Penha configurou verdadeira violência institucional contra os direitos humanos das mulheres, completo descaso contra estes direitos e total desrespeito aos princípios constitucionais do acesso à justiça e razoável duração do processo.

As recomendações da CIDH forçaram a inclusão da proteção das mulheres na política criminal brasileira, em clara ingerência internacional nesta seara ${ }^{9}$. Em face disso, foi criada a Lei Maria Penha publicada em 2006, inovadora ao estabelecer um sistema multidisciplinar de proteção às mulheres vítimas de violência doméstica. Segundo Fernandes (2013, p. 83), “[...] a lei permite aos aplicadores transformar o Direito em uma realidade de

\footnotetext{
${ }^{7}$ A Convenção de Belém do Pará, art. $2^{\circ}$, alínea $c$, firma que "[...] Entende-se que a violência contra a mulher abrange a violência física, sexual e psicológica [...] perpetrada ou tolerada pelo Estado ou seus agentes, onde quer que ocorra [...]" (OEA, 1994, n. p.)

${ }^{8}$ Segundo o Relatório da CIDH (2001), que o então marido da denunciante praticou contra ela uma tentativa de homicídio e outras agressões nos meses de maio e junho de 1983. As agressões perpetradas contra Maria da Penha pelo seu então marido originaram paraplegia irreversível, dentre outras enfermidades.

${ }^{9}$ Fala-se em ingerência, entretanto, ingerência legítima, uma vez que o Brasil já era signatário da Convenção de Belém do Pará (que não a toa levou o nome do local em que foi celebrada) e, portanto, aceitou os termos daquele compromisso internacional.
} 
justiça. E o tratamento diferencial estabelecido é imprescindível para se proteger a mulher, tratando-se de uma discriminação positiva [...]”.

Vários estudos têm sido desenvolvidos para aferir o nível de efetividade que o poder judiciário, outrora incapaz de dar uma resposta tempestiva para Maria da Penha Maia Fernandes, tem conseguido entregar resultados, tanto às vítimas de violência doméstica, quanto à própria sociedade. Ao mesmo tempo, é preocupante o crescimento da incidência de violência contra mulheres. Segundo o Atlas da Violência 2018, realizado pelo Instituto de Pesquisa Econômica Aplicada (IPEA), de modo geral, em 2016, 4.645 (quatro mil, seiscentos e quarenta e cinco) mulheres foram assassinadas no Brasil, o que representa uma taxa de 4,5 homicídios para cada 100 mil brasileiras, tendo-se ainda observado que, em 10 anos, houve o aumento de 6,4\% nesta taxa. Trazendo para a nossa realidade local, o Maranhão, embora não figure entre as unidades federativas com o maior índice de homicídios de mulheres no ano examinado pelo Atlas da Violência 2018, quando se considera a década, Rio Grande do Norte e Maranhão figuram como os estados com maiores aumentos nesta taxa, algo em torno de $130 \%$.

Em termos de feminicídios, o IPEA esclarece que a coleta dos dados analisados foi realizada junto ao Sistema de Informações sobre Mortalidade (SIM), o qual não disponibiliza informações específicas sobre feminicídios. Infere-se, portanto, que os dados analisados pelo IPEA informam homicídios de mulheres, mas sem ressalvas sobre as circunstâncias mais específicas de como o crime ocorreu. Apesar destas circunstâncias ${ }^{10}$, o IPEA reconhece e admite a existência do ciclo da violência doméstica, nos termos já expostos neste trabalho.

\footnotetext{
${ }^{10}$ Para estimar o número de feminicídios dentre o total de mortes por agressão, o IPEA valeu-se da metodologia elaborada pela demógrafa Jackeline Aparecida Ferreira Romio (2017), em sua tese "Feminicídios no Brasil, uma proposta de análise com dados do setor de saúde". O método proposto por Romio (2017) e utilizado pelo IPEA (2018) considera três categorias de feminicídio: reprodutivo, doméstico e sexual, em busca de “[...] índices mínimos que indiquem que as mortes estudadas tiveram como causa a condição social da mulher e discriminação por sexo contra mulheres [...]" (ROMIO, 2017, p. 165). Falando brevemente sobre as três categorias de feminicídio formuladas por Romio (2017), tem-se que, no feminicídio reprodutivo estão alocados os casos de aborto voluntário, que não são examinados pelo Atlas da Violência 2018; no feminicídio sexual, a catalogação se dá por meio do CID-10 - Y05, ou seja, agressão sexual por meio de força física e, por último, no feminicídio doméstico, em que se analisa também o dado do local do crime. A demógrafa assinala que o feminicídio doméstico é a categoria mais desafiadora, já que nem todo homicídio de mulher que ocorre em casa é feminicídio doméstico, podendo este acontecer em outros locais diversos da casa. Em que pese tal consideração, é necessário observar que, “[...] dada a característica de casos cometidos em maior proporção por contato físico direto, quando comparados com homicídios ocorridos na rua, e dos homicídios de mulheres serem cometidos, em maior proporção, em casa, enquanto os homicídios masculinos ocorrem, em sua maioria, em espaço público [...]" (IPEA, 2018, p. 47).
} 
[...] No entanto, a mulher que se torna uma vítima fatal muitas vezes já foi vítima de uma série de outras violências de gênero, por exemplo: violência psicológica, patrimonial, física ou sexual. Ou seja, muitas mortes poderiam ser evitadas, impedindo o desfecho fatal, caso as mulheres tivessem tido opções concretas e apoio para conseguir sair de um ciclo de violência [...]. (BRASIL, IPEA, 2018, p. 46).

Os resultados apontados pelo IPEA não são nada animadores e indicam que, apenas a edição da Lei Maria da Penha e a realização de campanhas informativas, voltadas tanto para vítimas quanto para agressores não tem sido suficiente.

Voltando os olhos para os dados fornecidos pelo Conselho Nacional de Justiça (CNJ), através dos Relatórios intitulados O poder judiciário na aplicação da Lei Maria da Penha, referente aos anos de 2017 e $2018^{11}$, tem-se os dados das unidades federativas como um todo ${ }^{12}$. O CNJ destaca que os indicadores constantes dos seus relatórios “[...] não significam o diagnóstico da violência existente contra as mulheres, mas sim a busca pelas instituições de Justiça para resolver o problema [...]” (BRASIL, 2017, p. 27). Neste sentido, em se tratando da quantidade média de casos novos de conhecimento criminais em violência doméstica contra a mulher, por Vara ou Juizado Especializado, em 2017, tem-se que "[...] os cinco tribunais mais demandados são TJMG (12.668 processos por Vara), o TJSC (6.764), o TJSP (4.778), o TJMA (4.727) e o TJMS (4.629) [...]” (BRASIL, 2017, p. 34). Em 2018, o CNJ informou que os tribunais mais demandados eram, “[...] TJSP [...] com 67.541 casos novos; o TJRS [...] com 66.355 processos; o TJMG [...] com 47.320; o TJRJ [...] com 46.340 processos [...]" (BRASIL, 2018, p. 13).

No total, comparando-se os números do CNJ, referente aos Relatórios de 2017 e 2018, verifica-se, na verdade, um salto no total de casos novos de conhecimento criminal que ingressaram nas Varas e Juizados Especializados em violência doméstica contra a mulher: o Relatório de 2017 contabilizou 334.088 (trezentos e trinta e quatro mil e oitenta e oito) casos desta espécie $^{13}$, enquanto esse número, conforme o Relatório de 2018, saltou para 452.988 (quatrocentos e cinquenta e dois mil, novecentos e noventa e oito) casos ${ }^{14}$. Destaca-se que, destes cômputos, estão excluídos os casos de feminicídio, pois, por se tratar de alteração

\footnotetext{
${ }^{11}$ Esclarece-se que, o Relatório de 2017, analisa dados consolidados em 2016 e o Relatório de 2018, examina dados consolidados em 2017.

${ }^{12} \mathrm{Ou}$ seja, não são especificados de acordo com a comarca ou circunscrição.

13 ،[...] Em 2016 ingressaram nos tribunais de justiça estaduais do país 334.088 casos novos de conhecimento criminais em violência doméstica contra a mulher [...]" (BRASIL, CNJ, 2017, p. 32).

14 “....] Em 2017 ingressaram nos tribunais de justiça estaduais do país 452.988 casos novos de conhecimento criminais em violência doméstica contra a mulher [...]” (BRASIL, CNJ, 2018, p. 12/13).
} 
legislativa recente ${ }^{15}$, a qual os tribunais ainda estão em fase de adaptação de seus sistemas para a coleta destes dados específicos ${ }^{16}$. Em que pese as dificuldades de adaptação dos tribunais, com o advento da qualificadora do feminicídio ao crime de homicídio, parte dos tribunais revisou os dados dos feminicídios referentes ao ano de 2016, constatando a monta de 1.287 (mil, duzentos e oitenta e sete) casos, além de ter contado, em 2017, com o registro de 2.643 (dois mil, seiscentos e quarenta e três) casos novos de feminicídio na justiça estadual do país (BRASIL, 2018, p. 19).

A análise dos dados fornecidos pelo CNJ permite inferir o aumento da ocorrência de crimes de violência doméstica contra as mulheres e acompanham a tendência crescente deste tipo de violência, de acordo com os Atlas da Violência dos anos de 2017 e 2018. Mesmo com a realização periódica de campanhas informativas e mutirões visando dar maior celeridade à resolução destas demandas, fato é que os números, em termos absolutos, não diminuíram. $\mathrm{Na}$ verdade, a partir destes números, a conclusão que se chega é que não bastou a inclusão das exigências de proteção às mulheres na política criminal brasileira, com a publicação de normas mais incisivas de salvaguarda das mulheres (Lei $\mathrm{n}^{\circ}$. 11.340/2006 e Lei $\mathrm{n}^{\circ}$. 13.104/2015), especialmente aquelas vítimas de violência doméstica e familiar, mais vulneráveis, dadas as especificidades deste tipo de violência.

A impressão que se tem é que as janelas continuam quebradas e o ambiente propício para que a violência aconteça.

\section{A PUNIÇÃO DOS CRIMES MENORES COMO BARREIRA AO CRESCIMENTO DA ASPIRAL ASCEDENTE DE VIOLÊNCIA}

Os relatórios do CNJ intitulados "O Poder Judiciário na Aplicação da Lei Maria da Penha", dos anos de 2017 e 2018, não fornecem informações sobre os assuntos mais

\footnotetext{
${ }^{15}$ Foi acrescido ao art. 121 do Código Penal, o inc. VI e o $§ 2^{\circ} \mathrm{A}$, inc. I e II, por meio da Lei ${ }^{\circ}$. 13.104/2015. A referida alteração legislativa criou a qualificadora do feminicídio nos crimes de homicídio, ou seja, se o homicídio é cometido contra a mulher por razões da condição do sexo feminino, sendo tais condições: a) a violência doméstica e familiar ou b) o menosprezo ou discriminação à condição de mulher (BRASIL, 1940, n. p.)

${ }^{16}$ Segundo o CNJ: “[...] Por se tratar de previsão em lei com edição recente, tendo sido incorporado como assunto nas tabelas processuais do CNJ apenas em 2016, alguns tribunais não dispõem dessas estatísticas - caso dos TJAP e TJAL. Outros tribunais relatam dificuldades em contabilizar esses casos, devido a problemas de parametrização em seus sistemas. Ainda que haja subnotificação e problemas de extração da informação, a movimentação processual dos casos de feminicídio é expressiva [...] (BRASIL, CNJ, 2018, p. 19)
} 
demandados na seara da violência doméstica nas Varas e Juizados Especializados, o que consiste em falha a ser sanada, pois, a partir deste diagnóstico, seria possível, inclusive, formular políticas públicas, como campanhas informativas e mutirões judiciários mais direcionados.

Em face disso, este estudo recorreu ao Relatório "Justiça em Números", também do CNJ, referente ao ano de $2016^{17}$, para se ter uma ideia dos crimes mais recorrentes na seara da violência doméstica. É importante ter conhecimento de tal circunstância, porque é recorrente a confusão na interpretação da Lei Maria da Penha: esta norma, ao longo dos seus 46 (quarenta e seis) artigos, tipifica apenas um crime, que é o previsto no art. 24-A da lei (descumprimento de medida protetiva de $\operatorname{urgência}^{18}$ ). Neste sentido, o que acontece é a prática de crimes previstos no Código Penal ou em leis esparsas, em situação de violência doméstica e familiar contra a mulher, circunstância esta que pode agravar ou qualificar a conduta delituosa ${ }^{19}$.

O "Justiça em Números" do ano de 2016 analisou e ranqueou em 20 (vinte) posições os assuntos ${ }^{20}$ mais demandados nas Varas e Juizados Especializados ( $1^{\circ}$ grau de jurisdição) e constatou que, no período analisado, dentre os assuntos mais demandados constam: crimes contra a liberdade pessoal/ameaça, na monta de 302.906 (trezentos e dois mil, novecentos e seis) casos, ocupando a $16^{a}$ posição; violência doméstica contra a mulher, correspondentes a 233.128 (duzentos e trinta e três mil, cento e vinte e oito) casos, ocupando a $18^{\text {a }}$ colocação,

\footnotetext{
${ }^{17}$ O Relatório "Justiça em Números" do ano de 2016 analisou dados do poder judiciário consolidados no ano de 2015. O "Justiça em Números" dos anos de 2017 e 2018 não foi utilizado nesta parte da análise porque não traz maiores detalhamentos sobre os assuntos das demandas, como faz o "Justiça em Números" do ano de 2016.

${ }^{18} \mathrm{O}$ art. 24-A, da Lei $\mathrm{n}^{\circ} .11 .340 / 2006$ estabelece que, descumprir decisão judicial que defere medidas protetivas de urgência possui pena de detenção de 03 (três) meses a 02 (dois) anos (BRASIL, 2006, n. p.)

${ }^{19}$ A título de exemplo, tem-se o art. 129, $\S 9^{\circ}$ do Código Penal, que qualifica a lesão corporal praticada sob os auspícios da violência doméstica: "[...] Se a lesão for praticada contra ascendente, descendente, irmão, cônjuge ou companheiro, ou com quem conviva ou tenha convivido, ou, ainda, prevalecendo-se o agente das relações domésticas, de coabitação ou de hospitalidade: Pena - detenção, de 3 (três) meses a 3 (três) anos [...]" (BRASIL, 1940, n. p.). Pode-se citar como exemplo também a ameaça, prevista no art. 147, do Código Penal: "[...] Ameaçar alguém, por palavra, escrito ou gesto, ou qualquer outro meio simbólico, de causar-lhe mal injusto e grave: Pena - detenção, de um a seis meses, ou multa [...]", mas que, quando praticada no contexto de violência doméstica, pode ter a sua pena aumentada, por ocasião da dosimetria da pena, em virtude do que dispõe o art. $7^{\circ}$, inc. II, da Lei $n^{\circ}$. 11.340/2006) (BRASIL, 2006, n. p.)

${ }^{20}$ Trata-se dos "[...] quantitativos de processos ingressados no ano de 2015 segmentados por classes e assuntos, segundo as tabelas processuais unificadas, as quais foram instituídas pela Resolução CNJ 46, de 18 de dezembro de 2007. [...] No cômputo do total de casos novos da Justiça Estadual algumas classes são excluídas, como é o caso dos precatórios judiciais, requisições de pequeno valor, embargos de declaração, entre outras. Todavia, nesta seção, o objetivo é conhecer a demanda para cada uma dessas classes em separado e, portanto, todas são consideradas. Com relação aos assuntos, é comum o cadastro de mais de um assunto em um mesmo processo, e neste caso, todos são contabilizados. Portanto, os números que serão apresentados não refletem a quantidade de processos ingressados na Justiça Estadual, mas tão somente a quantidade de processos cadastrados em determinada classe e/ou assunto [...]" (BRASIL, 2016, p. 141).
} 
seguido de lesão corporal decorrente de violência doméstica, com 230.142 (duzentos e trinta mil, cento e quarenta e dois) casos, na $19^{a}$ colocação.

Esse dado representa exatamente a espiral ascendente em que se configuram os crimes de violência doméstica, ou seja, a ampla incidência de crimes como ameaça, considerados menores em um contexto de repetição e agravamento. Diz-se isso porque o dado indica a maior incidência de crimes de ameaça no cômputo geral dos tribunais de justiça do que de lesão corporal. É possível inferir, portanto, que a repressão destes crimes entendidos como menores poderia evitar, em grande parte, a ocorrência dos crimes maiores, como as lesões corporais mais graves e feminicídios.

Ressalta-se que, o fato deste trabalho referir-se aos crimes contra a liberdade pessoal, contra a honra ou contravenções penais como menores não denota menosprezo a eles. Significa apenas que este artigo tomou como critério a quantidade de pena prevista para o delito, de modo que os crimes mencionados podem ser encarados como menores quando comparados com a quantidade de pena imposta à lesão corporal ou homicídio.

Tomando por base a teoria das janelas quebradas de Wilson e Kelling (1982), a premissa principal desta teoria é a de que a exemplar repressão dos crimes menores tem efeito preventivo contra crimes mais violentos. Em termos de violência doméstica esta premissa é viável e pode trazer resultados mais concretos. Entende-se ainda que não se trata de expansionismo penal, uma vez que, desde a publicação da Lei Maria da Penha, em 2006, o endurecimento do tratamento aos agressores domésticos é uma realidade que tem se tentado implementar pelos vários órgãos membros da rede de proteção à mulher, fato que demonstra que a política criminal brasileira já fez esta opção em 2006 e a tem reiterado ao longo dos anos, como se vê com o advento da Lei ${ }^{\circ}$. 13.104/2015, por exemplo.

Apesar disso, o sentimento de que as janelas permanecem quebradas e o ambiente ainda é receptivo para os agressores domésticos permanece. Esta percepção é endossada pelos números apresentados pelos Atlas da Violência dos anos de 2017 e 2018 e pelos números do CNJ: ambos apontam altas nas taxas de violência contra as mulheres e nas demandas desta natureza que são levadas ao poder judiciário, o que parece ser uma consequência lógica.

Os dados quanto ao nível de efetividade das respostas que o poder judiciário concede nos casos de violência doméstica, especialmente no que diz respeito às execuções das sentenças condenatórias são vagos, especialmente quando comparados com a demanda de violência doméstica que os tribunais recebem. A demanda é muito grande e o índice de 
execução muito baixo. Segundo o Relatório "O Poder Judiciário na Aplicação da Lei Maria da Penha" do ano de 2017, os tribunais com maiores demandas, como o TJMG, TJSC e TJSP, baixaram da execução criminal, 1.105 (mil, cento e cinco), 1.252 (mil, duzentos e cinquenta e dois) e 102 (cento e dois) processos, ou seja, uma resposta muito aquém em termos de efetividade, quando se analisa tribunais considerados como de grande porte. Em termos de vagueza, pode-se citar o TJMA, também considerado no ano de 2017 como um dos tribunais de maior demanda (4.727) processual, mas que não prestou informações sobre a quantidade de processos em fase de execução penal baixados.

Em 2018, o mesmo relatório, ao analisar as execuções penais dos casos de violência doméstica, registrou a tendência de alta demanda processual e baixo índice de execução penal, considerando a grande demanda existente.

É fundamental fazer com que a sociedade sinta a efetividade das decisões do poder judiciário na seara da violência doméstica. Os números analisados neste trabalho apontam para um vácuo existente entre a fase conhecimento do processo penal e a sua fase de execução: não se percebe a mesma amplitude da demanda de processos de violência doméstica que ingressam nas varas e juizados especializados alcançar a execução penal. Ainda que se faça a soma entre execuções iniciadas, execuções pendentes e processos baixados da execução, os números desta etapa ainda ficam muito aquém da fase de conhecimento. Esta discrepância, segundo a broken windows theory, passa a impressão de no one cares para os agressores domésticos, ou seja, o sentimento de impunidade que incentiva a prática de mais crimes desta natureza.

\section{CONSIDERAÇÕES FINAIS}

Ao longo deste trabalho sustentou-se a aplicabilidade da broken windows theory, dos cientista sociais Wilson e Kelling (1982), a um campo de incidência mais restrito do que o proposto pelos formuladores da teoria. Restringindo-se o espectro da broken windows theory aos casos de violência doméstica contra as mulheres é possível frear os avanços das taxas de crimes desta natureza.

Havendo a atuação mais célere e mais eficiente do poder judiciário, é possível diminuir o espaço temporal entre o processo de conhecimento da demanda criminal e a sua fase de execução penal, especialmente no que diz respeito aos crimes menores, ou seja, 
aqueles cujas penas são diminutas, quando comparados com crimes como lesões corporais mais graves e feminicídios.

Conseguindo-se processar e julgar estes crimes menores e, nos casos em que se obtiver a condenação do agressor, executá-los, será possível demonstrar às vítimas e à sociedade que não existe ambiente propício para práticas repugnantes como a violência doméstica. A melhoria na prestação da atividade jurisdicional, neste sentido, seria capaz de retribuir penalmente as ofendidas e prevenir o agravamento do ciclo da violência doméstica. Em outras palavras: uma atuação mais célere e eficiente das instituições do sistema de justiça, em especial, o poder judiciário, demonstraria que as janelas, outrora quebradas, foram consertadas. Desta maneira, o ciclo das agressões domésticas perderia o fôlego logo no início, reduzindo as chances de evoluir para crimes mais graves, circunstância esta que, inevitavelmente, repercutiria nos índices de violência contra as mulheres, diminuindo-os.

\section{REFERÊNCIAS}

BRASIL. Constituição da República Federativa do Brasil. Brasília, DF: Diário Oficial da União, 1988. Disponível em http://www.planalto.gov.br/ccivil_03/constituicao/constituicao.htm. Acesso em: 01 ago. 2019.

BRASIL. Instituto de Pesquisa Econômica Aplicada. Fórum Brasileiro de Segurança Pública. Atlas da Violência 2018. Brasília, DF: IPEA, FBSB, 2018. Disponível em http://www.ipea.gov.br/portal/images/stories/PDFs/relatorio_institucional/180604_atlas_da_v iolencia_2018.pdf. Acesso em: 25 jun. 2019.

BRASIL. Instituto de Pesquisa Econômica Aplicada. Fórum Brasileiro de Segurança Pública. Atlas da Violência 2017. Brasília, DF: IPEA, FBSB, 2017. Disponível em: http://www.ipea.gov.br/portal/images/170602_atlas_da_violencia_2017.pdf. Acesso em: 25 jun. 2019.

BRASIL. Decreto-Lei n. ${ }^{\circ}$ 2.848, de 7 de dezembro de 1940. Código Penal. Brasília, DF: Diário Oficial da União, 1940. Disponível em http://www.planalto.gov.br/ccivil_03/decretolei/del2848compilado.htm. Acesso em: 03 ago. 2019.

BRASIL. Conselho Nacional de Justiça. O Poder Judiciário na aplicação da Lei Maria da Penha 2017. Brasília, DF: CNJ, 2017. Disponível em http://www.cnj.jus.br/files/conteudo/arquivo/2017/10/ba9a59b474f22bbdbf7cd4f7e3829aa6.p df. Acesso em: 01 ago. 2019.

BRASIL. Conselho Nacional de Justiça. Justiça em Números 2016. Brasília, DF: CNJ, 2016. Disponível em https://www.cnj.jus.br/files/conteudo/arquivo/2016/10/b8f46be3dbbff344931a933579915488. pdf. Acesso em: 01 ago. 2019. 
BRASIL. Conselho Nacional de Justiça. O Poder Judiciário na aplicação da Lei Maria da Penha 2018. Brasília, DF: CNJ, 2018. Disponível em http://cnj.jus.br/files/publicacoes/arquivo/5f271e3f54a853da92749ed051cf3059_18ead26dd2a b9cb18f8cb59165b61f27.pdf. Acesso em: 01 ago. 2019.

BRASIL. Lei $\mathbf{N}^{\mathbf{o}}$ 11.340, de 7 de agosto de 2006. Cria mecanismos para coibir a violência doméstica e familiar contra a mulher, nos termos do $\S 8^{\circ}$ do art. 226 da Constituição Federal, da Convenção sobre a Eliminação de Todas as Formas de Discriminação contra as Mulheres e da Convenção Interamericana para Prevenir, Punir e Erradicar a Violência contra a Mulher; dispõe sobre a criação dos Juizados de Violência Doméstica e Familiar contra a Mulher; altera o Código de Processo Penal, o Código Penal e a Lei de Execução Penal; e dá outras providências. Brasília, DF: Diário Oficial da União, 2006. Disponível em http://www.planalto.gov.br/ccivil_03/_ato2004-2006/2006/lei/111340.htm. Acesso em: 03 ago. 2019.

DAMATTA, Roberto. A casa e a rua: espaço, cidadania, mulher e morte no Brasil. Rio de Janeiro: Editora Rocco, 1997.

DIAS, Maria Berenice. Lei Maria da Penha: a efetividade da Lei 11.340/2006 de combate à violência doméstica e familiar contra a mulher. 4. ed. rev. atual. e ampl. São Paulo: Revista dos Tribunais, 2015.

FERNANDES, Valéria Diez Scarance. Lei Maria da Penha: o Processo Penal no caminho da efetividade. 2013. Tese (Doutorado) Pontifícia Universidade Católica de São Paulo, São Paulo, 2013.

ORGANIZAÇÃO DOS ESTADOS AMERICANOS. Comissão Interamericana de Direitos Humanos. Relatório no. 54/01. Caso no. 12.051. [S.1.]: OEA, CIDH, 2001. Disponível em https://www.cidh.oas.org/annualrep/2000port/12051.htm. Acesso em: 25 mar. 2019.

ORGANIZAÇÃO DOS ESTADOS AMERICANOS. Convenção interamericana para prevenir, punir e erradicar a violência contra a mulher, "convenção de Belém do Pará". [S.1.]: OEA, CIDH, 1994. Disponível em

http://www.cidh.org/Basicos/Portugues/m.Belem.do.Para.htm. Acesso em: 25 mar. 2019.

MATTOS, Marcio. Efeitos vizinhança e eficácia coletiva: a relevância do contexto na explicação sociológica. Revista Sociedade e Estado, v. 33, n. 1, jan./abr. 2018.

ODON, Tiago Ivo. Tolerância Zero e Janelas Quebradas: sobre os riscos de se importar teorias políticas. Brasília, DF: Núcleo de Estudos e Pesquisas, CONLEG, Senado, 2016. (Texto para Discussão ${ }^{\circ}$. 194). Disponível em http://www2.senado.leg.br/bdsf/handle/id/519162. Acesso em: 25 mar. 2019.

ROMIO, Jackeline Aparecida Ferreira. Feminicídios no Brasil, uma proposta de análise com dados do setor de saúde. 2017. Tese (Doutorado) - Universidade Estadual de Campinas, Campinas, 2017. Disponível em 
http://repositorio.unicamp.br/jspui/bitstream/REPOSIP/330347/1/Romio_JackelineAparecida Ferreira_D.pdf. Acesso em: 01 ago. 2019.

ROXIN, Claus. Política criminal y sistema del derecho penal. 2. ed. 1. reimp. Buenos Aires: Editora Hammurabi, 2002.

SAMPSON, Robert J. Great American City: Chicago and the enduring neighborhood effect. Chicago: University of Chicago Press, 2012.

WACQUANT, Loïc. The "Scholarly Myths" of the New Law and Order Doxa. Socialist Register, 2006. Disponível em

https://socialistregister.com/index.php/srv/article/view/5845/2741. Acesso em: 01 ago. 2019.

WILSON, James Q.; KELLING, George L. Broken Windows. The police and neightborhood safety. The Atlantic, 1982. Disponível em

https://www.theatlantic.com/magazine/archive/1982/03/broken-windows/304465/. Acesso em: 25 jun. 2019. 